\title{
Endoscopic Resection of a Juxtapapillary Gangliocytic Paraganglioma
}

A 63-year-old man was hospitalized for work-up of noncardiac chest pain. Laboratory data on admission showed hypochromia (25pg; normal range $27-31 \mathrm{pg}$ ) and microcytosis (79fl; normal range 8095fl), with a normal hemoglobin level of $14.4 \mathrm{~g} / \mathrm{dl}$ (normal range $14-18 \mathrm{~g} / \mathrm{dl}$ ). An upper gastrointestinal endoscopic examination revealed a submucosal polypoid lesion adjacent to the major papilla (Figure 1). Biopsy specimens from the mucosa overlying this lesion showed normal duodenal mucosa. An endosonographic examination was also carried out, and it showed a round, well-demarcated, hypoechoic, submucosal tumor in the third layer just distal to the papilla of Vater (Figure 2). There was no invasion of the muscularis propria. There were no pathological lymph nodes around the duodenum and celiac trunk.

It was decided to remove the process for histological evaluation. The lesion was approached with a duodenoscope. A mucosectomy was carried out after submucosal injection with normal saline. Arterial bleeding developed, which was controlled with an injection of $1: 10000$ epinephrine and placement of four clips. After hemostasis, a round, yellow tumor

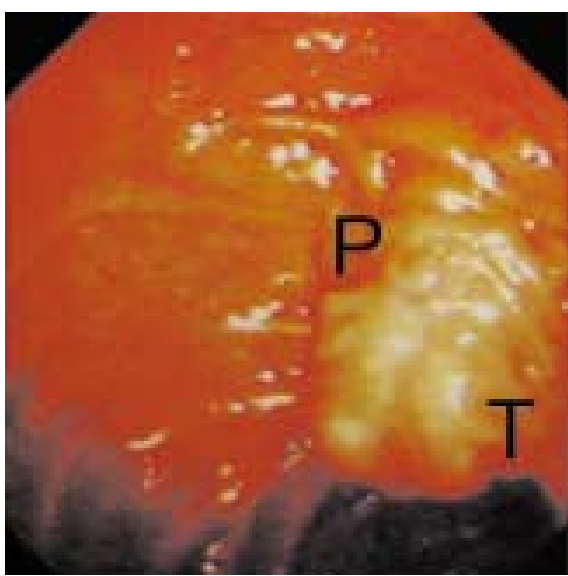

Figure 1 A polypoid tumor $(\mathrm{T})$ is seen adjacent to the papilla of Vater $(P)$. was visualized in the submucosa (Figure 3). The submucosal tumor was removed with a snare. The opening of the major papilla was not touched. Repeat bleeding occurred on the same day of the procedure and was treated with placement of two more clips (Figure 4). An endoscopic check-up examination 2 days later

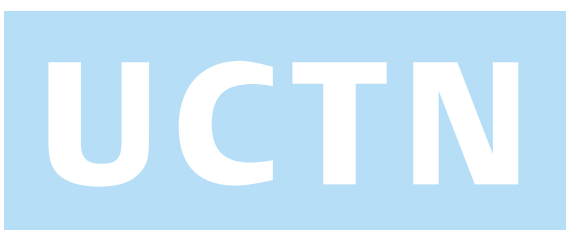

showed no signs of further or impending bleeding. No early or late complications, such as pancreatitis or stenosis of the common bile duct, developed.

The histological examination showed a gangliocytic paraganglioma, $11 \mathrm{~mm}$ in size. There was a characteristic histologi-

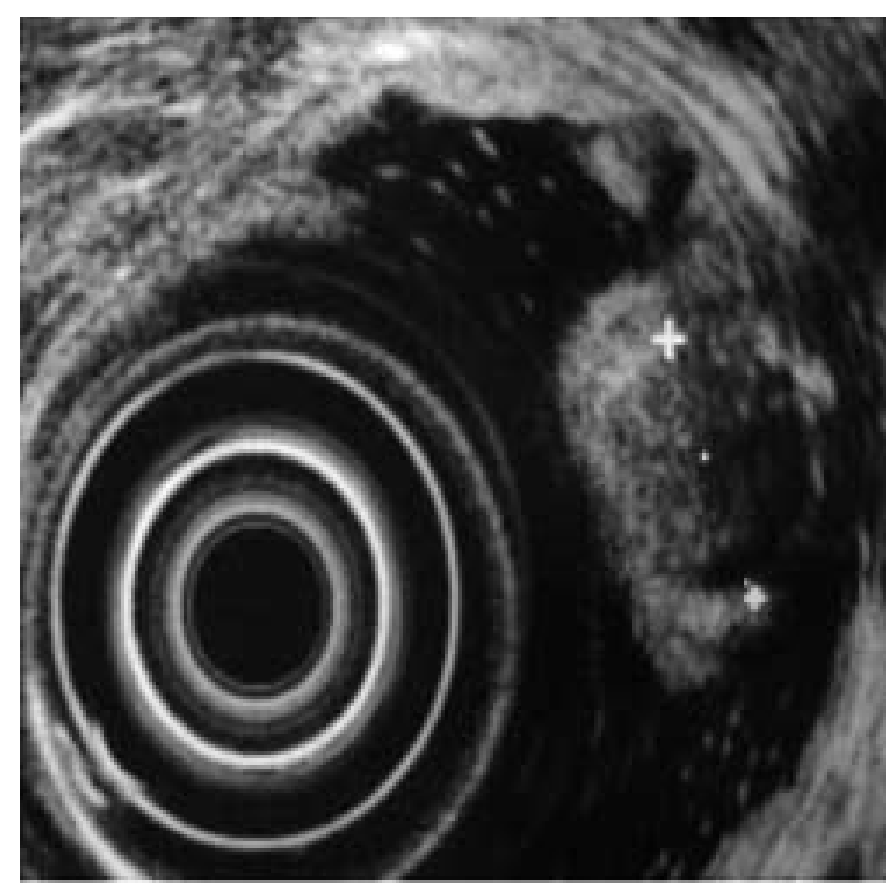

Figure 2 Endoscopic ultrasonography $(12 \mathrm{MHz})$ of the tumor, showing a round, hypoechoic lesion measuring $1.1 \mathrm{~cm}$ in the submucosa. There is no invasion of the muscularis propria.

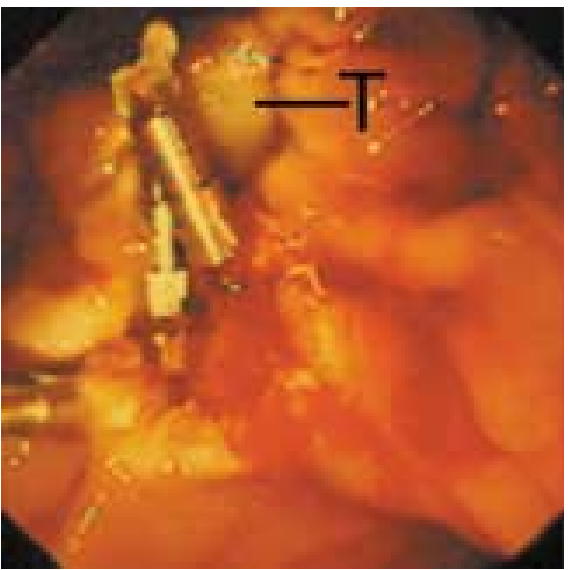

Figure 3 After ablation of the mucosa and control of bleeding in the distal margin of the lesion, requiring hemostasis with clips, a yellow, roundish tumor $(\mathrm{T})$ was visualized.

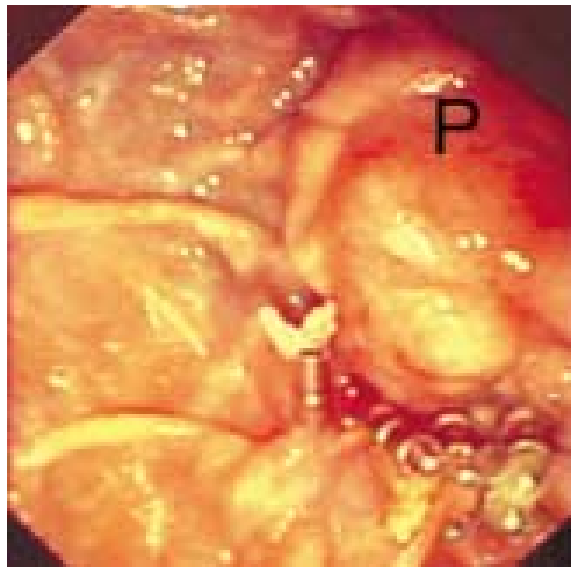

Figure 4 The situation at end of the intervention, after hemostasis and snare resection of the tumor. No lesions are evident at the papilla of Vater $(\mathrm{P})$. There is some tissue edema due to injection of the diluted epinephrine solution. 
cal pattern, with three distinct cell populations: epithelial cells in nests and arranged in a trabecular pattern, spindle cells in fascicles, and large, irregularly shaped cells reminiscent of gangliocytes.

Gangliocytic paragangliomas were first described in 1962 [1]. Since then, more than 130 cases have been reported [2]. Most of these tumors were removed surgically. Gangliocytic paragangliomas are mostly benign, but there have been reports of regional lymph-node metastasis [3]. Duodenal gangliocytic paragangliomas are found most often in close proximity to the major papilla [4]. Endoscopic removal of a gangliocytic paraganglioma is an alternative to surgical resection when regional lymph-node involvement has been excluded with imaging studies, as in the present case using endoscopic ultrasound. However, care has to be taken to avoid injury to the papilla, and one must be prepared to encounter and treat bleeding.

\section{P. Hengstler, J. Binek, C. Meyenberger}

Department of Internal Medicine, Division of Gastroenterology, Kantonsspital St. Gallen, St. Gallen, Switzerland.

\section{References}

${ }^{1}$ Taylor HB, Helwig EB. Benign nonchromaffin paragangliomas of the duodenum. Virchows Arch A 1962; 335: 356

${ }^{2}$ Nakamura T, Ozawa T, Takehira Yet al. Endoscopic resection of gangliocytic paraganglioma of the minor duodenal papilla: case report and review. Gastrointest Endosc 2002; 55: 270-273

${ }^{3}$ Hashimoto S, Kawasaki S, Matsuzawa Ket al. Gangliocytic paraganglioma of the papilla of Vater with regional lymph node metastasis. Am J Gastroenterol 1992; 87: 1216 - 1218

${ }^{4}$ Scheithauer BW, Nora FE, LeChago Jet al. Duodenal gangliocytic paraganglioma: clinicopathologic and immunohistochemical study of 11 cases. Am J Clin Pathol 1986; 86: 559-565

\section{Corresponding Author}

\section{P. Hengstler, MD}

Innere Medizin

Fachbereich Gastroenterologie

Kantonsspital St. Gallen

9007 St. Gallen

Switzerland

Fax: $\quad$ +41-71-494-2862

E-mail: peter.hengstler@kssg.ch 